\title{
Promoting a culture of civility in nursing education and practice
}

\author{
Jennifer L. Milesky ${ }^{1}$, Diana-Lyn Baptiste ${ }^{* 1}$, Cynthia Foronda ${ }^{1}$, Alice E. Dupler ${ }^{2}$, Anne E. Belcher ${ }^{1}$ \\ ${ }^{1}$ School of Nursing, Johns Hopkins University, Baltimore, MD, United States \\ ${ }^{2}$ School of Nursing and Human Physiology, Gonzaga University Spokane, WA, United States
}

Received: March 11, 2015

DOI: $10.5430 /$ jnep.v5n8p90
Accepted: May 13, 2015

Online Published: May 27, 2015

\begin{abstract}
Incivility is a growing problem in nursing education and clinical nursing. Incivility often is underreported and tolerated by nurses, faculty, and students. It is necessary to bring attention to the problem of incivility and discuss its negative impact on teaching, learning, and patient outcomes. The aim of this paper is to a) explore what is known about incivility by reviewing current literature and b) recommend strategies to promote a culture of civility in nursing education and clinical nursing.
\end{abstract}

Key Words: Civility, Nursing, Education, Incivility, Students, Faculty, Cultural humility, Interprofessional education

\section{INTRODUCTION}

For decades, nursing has embraced the paradoxical culture of being the most caring and trusted profession whilst "eating their young". Novice nurses enter the profession and often find an environment that is less than welcoming. Rather than being mentored and nurtured, many new nurses recall being bullied, belittled and abused. Nurses and nurse educators have tolerated an environment where they are each other's adversaries rather than supporters. There is a palpable culture of egos relating to years of experience and rank. This culture may be a contributing factor to the nursing and nurse faculty shortage as new graduate nurses leave the profession at an alarming rate. ${ }^{[1,2]}$ The resulting environment lacks of teamwork, communication, professional behaviors, and leads to organizational disruption, and poor patient outcomes. ${ }^{[3-5]}$ This taboo yet dangerous problem begs the question of where this behavior begins and how to curtail it.

Incivility occurs within the nursing profession at many levels leading to diminished trust in leadership, threats to the dig- nity of others, and decreased productivity. ${ }^{[6]}$ Incivility has a broad definition, including behaviors such as lack of respect, absence of honoring differences, rudeness, or unsociable speech with the most drastic effects being violent behavior. $^{[2,7]}$ Nurses are considered a historically oppressed group due to a long history of power imbalance. ${ }^{[8]}$ This history may contribute to a phenomenon of oppressed group behavior.

Incivility in nursing is an occurrence most nurses will privately acknowledge; however, they are hesitant to publicly bring forward for 1) fear of appearing as a complainer or a tattler, 2) fear of irreversible political stigma, thus, ruining one's career, 3) fear being failed out of a program or losing one's job, 4) fear of causing controversy, 5) choosing to avoid the conflict as a coping strategy, or 6) feeling the effort would be futile. There are many contexts of incivility in nurse education and practice. The aim of this paper is to discuss incivility by reviewing current literature and recommending strategies to promote a culture of civility in nursing education and clinical nursing.

*Correspondence: Diana-Lyn Baptiste; Email: dbaptis1@jhu.edu; Address: 525 N. Wolfe Street, Baltimore, MD 21205, United States. 


\section{LiteratuRE REVIEW}

Clark performed a mixed-methods survey comprised of a convenience sample of nurses and nursing students who attended national conferences. ${ }^{[9]}$ The study surveyed the two groups' experiences with academic incivility. The author found the most frequently reported uncivil student behaviors by faculty were holding distracting conversations, demanding make-up assignments, extensions, or grade changes, and using the computer for activities not related to class. The most frequently reported uncivil faculty behaviors cited by students were arriving late for class, holding distracting conversations, and leaving class early. Uncivil behaviors among faculty, while not occurring with the highest frequency, included refusal to answer questions, making condescending remarks or "put downs", rude behavior, being unavailable, distant or cold, or exerting rank or superiority.

In 2013, an editorial review published by Hutchison et al. described violence towards nurses in the workplace. ${ }^{[10]}$ The authors of the literature review analyzed 18 papers with the earliest publication being in 2007. The review included other literature reviews, qualitative pieces, and surveys, outlining the problem of violence against nurses from patients, their families and other staff. The authors described the effects of decreased confidence, emotional hardship and decreased job satisfaction. Nurses indicated that they had an increase in confidence and enhanced work performance when steps were taken to reduce violence including changes in policy or education. ${ }^{[10]}$ The authors recognized the need for further research to explore the indirect effects of incivility in the workplace among nurses on patients and families.

A review by Luparell analyzed connections between the occurrence of incivility in academia and clinical settings. ${ }^{[4]}$ Luparell argued that "today's students are tomorrow's colleagues", therefore, uncivil behavior must be studied and intervened upon before students even become nurses (p. 92). This review acknowledged the connection between incivility in nursing school and the continued culture when students officially entered the profession. The authors reiterated that nurses who are bullied in the practice setting are more likely to leave the profession. ${ }^{[4]}$

In the academic setting, Luparell noted that students reported being disrespected by faculty, nurses in the clinical setting, and their peers. ${ }^{[4]}$ The incivility experienced between peers was not explored further. Incivility was a concern in the academic setting because managing incivility required time and energy. Conversely, the energy a student puts students to believe this is the "norm" in nursing, predisposing them to continue this unhealthy behavior after graduation. Thus, role modeling and setting an example of a professional environ- ment is critical.

In a review on student incivility, Robertson examined research and non-research articles. ${ }^{[11]}$ Robertson defined incivility as "behaviors indicative of disrespect, manifested in the form of spoken words, gestures, or actions; intent to be disrespectful; and transient or permanent cessation of the learning process as a result of the inciting behavior" (p. 21). Robertson noted also that progressing uncivil nursing students invites them to behave as uncivil nurses, and managing incivility in the classroom and clinical setting monopolizes faculty time that should be used for teaching and mentoring.

Robertson's review differed from the others by discussing possible causes of students' uncivil behavior. Robertson cited possible causes as maladaptive coping to high levels of stress, time management issues, role strain, or financial or health stressors. The article highlighted challenges that may influence uncivil behaviors such as mental health and instability, generational differences between students and faculty, and the students' perceptions of themselves as a "consumer". A common theme of the literature was that higher anxiety levels preceded higher levels of incivility. Faculty raise the anxiety levels of students by arriving late, having unclear expectations, changing or having a poorly constructed syllabus, or setting a cold, unwelcoming or disrespectful tone in the classroom or clinical setting. The review cited several instances of evidence of a connection between students' uncivil academic behavior and incivility in the clinical or work setting. It is a fair assumption that the student who behaves unprofessionally or lacks civility in one environment is at high risk of misbehaving in others as well.

Following the review, Robertson made several recommendations for managing incivility in nursing education. The first was to decrease student anxiety by setting clear expectations and constructing a quality syllabus. The second was to set ethical standards to be met by both students and faculty, and to employ policies to enforce these standards. These actions assist to provide safety and confidence to both students and faculty. Robertson states, "a well-written protocol not only affords clarity and guidance, but it also promotes the consistent handling of classroom incivility" (p. 25). ${ }^{[1]}$

\section{Culture of Civility}

The culture of incivility in nursing is well documented and its effects are far reaching. Students who experience incivility in the academic setting feel anxiety and suffer poor performance. They may leave their nursing programs or be acculturated to become uncivil nurses. Faculty who experience incivility suffer anxiety, poor performance, or may leave academia altogether. Incivility in the clinical setting 
leads to psychiatric affects, poor work performance, poor work environments, and poor patient outcomes. ${ }^{[6,12]}$ The culture of incivility contributes to the nation-wide nursing and nursing faculty shortage by causing nurses, faculty and especially novice nurses, to leave the profession altogether at alarming rates. ${ }^{[2,6]}$

Several pioneers in nursing have studied and written about incivility of nursing faculty. Cynthia Clark is a renowned nurse researcher who has studied incivility in nursing and developed instruments to assist in measuring healthy work environments. ${ }^{[13]}$ In the text, The black academic's guide to tenure without losing your soul, Rockquemore and Laszloffy present the challenges of being a junior faculty member in the culture of academia as well as strategies on how to navigate this shockingly different culture successfully. ${ }^{[14]}$

Peter Pronovost is an anesthesiologist turned world renowned pioneer in patient safety and healthy and effective environments in healthcare. ${ }^{[5]}$ He has not only acknowledged the existence of incivility in healthcare, he has made it his life mission to address it by creating training programs that transform work environments. Through training in leadership, patient safety, conflict resolution, teamwork, interprofessional understanding, and communication; his work has influenced healthcare institutions globally. He has openly shared stories of physician-to-physician incivility as well as interprofessional incivility (i.e., physician-to-nurse). His research has demonstrated repeatedly that safe and just work cultures in healthcare improve patient outcomes. Incivility has been visible in the healthcare arena posing multiple implications, though, many consider it politically incorrect to acknowledge.

\section{LEGAL IMPLICATIONS}

Legally speaking, faculty and students concurrently have constitutional rights under the First Amendment to speak. ${ }^{[15-18]}$ School administrators are prohibited from mandating what is read, spoken or heard in the classroom. However, administrators can prohibit true threats of violence without infringing on First Amendment rights. ${ }^{[18]}$ If a reasonable person would interpret the spoken language as a "serious expression of intent to cause a present or future harm", this action can be interpreted as a true threat of violence, extending beyond protected speech. ${ }^{[18]}$

Uncivil or threatening speech must be knowingly and intentionally spoken to the person to whom the words or threat is directed, or to a third party. ${ }^{[17,18]}$ Subjective intent to act on the threat is not the basis upon which legal intervention may be initiated. Without intent to communicate a potential threat, a faculty member or student will not lose their protec- tion under the First Amendment. ${ }^{[18]}$ Schools may regulate faculty and student speech when uncivil speech substantially interferes with rights of other students or when it interferes with the work of the school. ${ }^{[17]}$

This includes school regulations focused on student viewpoints so long as in doing so, the regulations facilitate an important government interest and the behavior occurs on school grounds. ${ }^{[18]}$ Schools are not required to allow incivility evidenced by intentionally harmful words that could be perceived as a threat. Protection under the First Amendment is not absolute. ${ }^{[18]}$ When incongruent with its basic mission, schools are not required to tolerate incivility. ${ }^{[17]}$ Faculty members should take action to prohibit incivility and establish appropriate standards of conduct. Nurses, nurse faculty members, and administrators must discuss and consider incivility in the context of the law.

\section{RECOMMENDATIONS}

The intent of this article is not to draw negative attention to the authors' beloved profession of nursing; rather, the hope is to draw attention to the issue for the betterment of the profession. Several suggestions are provided to influence and drive a culture change in nursing education and clinical nursing (see Table 1). The first recommendation is for faculty members to reflect upon themselves to identify areas for improvement. Faculty must strive to set an example for students regarding civil and professional behavior. Students look up to faculty to teach theory and clinical skills, but also as a model of how to behave as a professional nurse. Faculty need to maintain the proper level of decorum to teach nursing students how to behave, and the behavior to expect, in the clinical setting. If nursing students are developed in an environment of support and mutual respect, they are less likely to tolerate or model incivility in their own clinical practice.

A second suggestion is to train and educate faculty and students regarding civility and cultural humility in the academic environment and in the workplace. One should not assume that faculty members are knowledgeable about the incidence or effects of incivility in nursing nor have they been educated about cultural humility. In this case, cultural humility is intended to extend and encompass any type of diversity be it ethnicity, age, religion, sexual orientation, or even interprofessional differences. Education regarding academic incivility and cultural humility will bring the problem to the forefront, identify its severity, and provide strategies to approach various issues. Training will clarify expectations and understanding regarding tolerated behaviors, resources available and the intended culture of nursing. This education is needed to equip faculty and students to identify their own areas for improvement, identify inappropriate behaviors, and 
seek the proper channels to resolve problems rather than adding to the toxicity of the situation.

The third suggestion from the literature was the need for further research, policy development and enforcement regarding ethics and uncivil behavior. ${ }^{[19]}$ Administrators must be trained in leadership theory and reward colleagues for acts of teamwork rather than individualism. Further, leaders must be prepared to intervene when incivility is exhibited and affecting morale. Students and faculty often feel as though they are not protected against uncivil behavior and if they speak up, they will be negatively stigmatized. This perception is why conflict resolution and uniform enforcement of policy is so important. If faculty and students feel unprotected, they are more likely to react to incivility with incivility further perpetuating the problem.

In exploring the literature for information regarding competition among nursing students, a chasm was noted. No literature regarding competitiveness among nursing students was located. In the literature about incivility in nursing education, the focus was disproportionately representative of incivility towards faculty members. This trend is likely because faculty members are the ones who most often write and research about the topic. The literature also lacks evidencebased solutions.

Future directions would include further research regarding the root of the incivility in nursing culture and interventions to pursue a culture change. To facilitate this change, nurses may borrow from other disciplines such as the social or behavioral sciences. Simply identifying the uncivil behaviors and incidence of its perpetrators is clearly not the answer. This is not a "faculty" problem or "student" problem. It is a nursing problem which affects everyone from academia to the clinical setting where it ultimately affects patients and their families.

Table 1. Strategies for promoting a culture of civility

- $\quad$ Reflect/self-evaluate and identify personal strengths and areas for improvement

- Model positive behaviors of the professional nurse

- $\quad$ Educate about personality types and diversity in thinking to help better understand self and others

- $\quad$ Set guidelines for students about mutual respect

- $\quad$ Create a safe, inclusive and judgment-free environment

- $\quad$ Provide training in communication, teamwork, and leadership

- $\quad$ Advocate for institution-wide cultural humility training

- $\quad$ Drive research, policy development, and enforcement regarding incivility considering ethical and legal

\section{Conclusion}

Incivility in nursing is a widespread problem that negatively affects nursing students, faculty members and clinical nurses. There is evidence to suggest this problem spreads from academia to the clinical environment. The problem is farreaching, causing nurses and faculty to leave the profession in the midst of a national shortage. Incivility leads to toxic work environments that adversely affect patients. Incivility negatively impacts persons involved as interactions may be reciprocal in nature. ${ }^{[20]}$ It is imperative that faculty, students, and nurses recognize the importance of establishing a meaningful dialogue to resolve conflicts. ${ }^{[20]}$ There is abundant support in the literature for promoting a culture of civility, but empirical studies to investigate factors that influence uncivil behaviors are lacking. Future efforts must address legal implications and policy targeted to manage incivility in the workplace and learning environments. Research is warranted to formally identify the existence of incivility and develop best practices to combat it. With this knowledge, the culture of nursing will be improved leading to optimal learning environments, productive work environments, and positive patient outcomes.

\section{CONFlicts OF InTEREST Disclosure}

The authors declare that there is no conflict of interest statement.

\section{REFERENCES}

[1] Jones CB, Gates M. The costs and benefits of nurse turnover: A business case for nurse retention. The Online Journal of Issues in Nursing. 2007; 12(3): Manuscript 4.
[2] Sprunk EA, LaSala KB, Wilson VL. Student incivility: Nursing faculty lived experience. Journal of Nursing Education and Practice. 2014; 4(9): 1-12. http://dx.doi.org/10.5430/jnep.v4n9p1

[3] Burger KG, Kramlich D, Malitas M, et al. Application of the sym- 
phonological approach to faculty-to-faculty incivility in nursing education. J Nurs Educ. 2014; 53(10): 563-568. PMid:25275989 http://dx.doi.org/10.3928/01484834-20140922-02

[4] Luparell S. Incivility in nursing: The connection between academia and clinical settings. Crit Care Nurse. 2011; 31(2): 92-95. PMid:21459868 http://dx.doi.org/10.4037/ccn2011171

[5] Pronovost P, Vohr E. Safe patients, smart hospitals. New York: Hudson Street Press; 2010.

[6] Luparell S. Incivility in nursing education. Imprint. 2008; 55(3): 42-46. PMid: 18512573

[7] Williams RB. The rise of incivility and bullying in America. 2012.

[8] Dubrosky R. Iris Young's five faces of oppression applied to nursing. Nurs Forum. 2013; 48(3): 205-210. PMid:23889199 http: //dx.doi.org/10.1111/nuf . 12027

[9] Clark CM. Faculty and student assessment of and experience with incivility in nursing education. J Nurs Educ. 2008; 47(10): 458-465. http://dx.doi.org/10.3928/01484834-20081001-03

[10] Hutchinson M, Jackson D, Haigh C, et al. Editorial: Five years of scholarship on violence, bullying and aggression towards nurses in the workplace: What have we learned? J Clin Nurs. 2013; 22(7-8): 903-905. PMid:23480497 http://dx.doi.org/10.1111/jocn 12139

[11] Robertson JE. Can't we all just get along? A primer on student incivility in nursing education. Nurs Educ Perspect. 2012; 33(1): 21-26. http://dx.doi.org/10.5480/1536-5026-33.1.21
[12] Luparell S. The effects of student incivility on nursing faculty. J Nurs Educ. 2007; 46(1): 15-19. PMid:17302095

[13] Clark CM. Civility conversations to inspire and promote healthy workplaces. American Nurse Today. 2015 In Review.

[14] Rockquemore KA, Laszloffy T. The black academic's guide to winning tenure-without losing your soul. Boulder, CO: Lynne Reinner Publishers; 2008.

[15] Congress of the US. Constitution of the United States. USCS Const. Amend.1. 1789.

[16] Juhan SC. Free speech, hate speech and the hostile speech environment. Virginia Law Review. 2012.

[17] O'Neil RM. Second thoughts on the first amendment in higher education. Mississippi Law Journal. 2014.

[18] Porter v. Ascension Parish Sch., 2005 U.S. LEXIS 4387. (US Supreme Court certiorari denied by U.S., May 31, 2005). 2005.

[19] Clark CM, Springer PJ. Incivility in nursing education: A descriptive study of definitions and prevalence. Journal of Nursing Education. 2007; 46(1): 7-14. PMid:17302094

[20] Clark CM, Davis KBL. Faculty empowerment of students to foster civility in nursing education: A merging of two conceptual models. Nursing Outlook. 2011; 59: 158-165. PMid:21497862 http://dx.doi.org/10.1016/j.outlook.2010.12.005 